\author{
Clipboard \\ DOI $10.1007 / \mathrm{s} 12038-014-9427-y$
}

\title{
Biodiversity only makes sense in the light of evolution
}

Biodiversity is a key to human well-being. However universally acknowledged, this reality is not appreciated as much as one might imagine or hope. Having achieved a high standing in the Convention on Biological Diversity (CBD) in 1992, biodiversity appears to have gradually fallen from that position in the 20 years since. This is evidenced by the fact that most discussions and actions in relation to the CBD have now shifted to sustainable development and ecosystem services (Daily 1997), instead of focusing more directly on biodiversity values themselves. One reason for this fall in status seems to be linked to issues about the actual definition of 'biodiversity', whether used in a broad sense, including the diversity of genes, species, communities and ecosystems, or more narrowly defined as the diversity of species alone. While the close link between biodiversity and 'ecosystem services' is undeniable, biodiversity itself has long recognized links to human well-being, including 'option values' (see later) that are sometimes neglected (Faith 2012). The conservation of biodiversity and all its values is fundamental to strategies aimed at achieving the long-term goal of sustainable development. The CBD definition of biodiversity captures the importance of considering variation and its values at multiple levels, including genetic and trait variation (http://www.cbd.int/convention/articles/default.shtml? $a=c b d-02$ ). A model that is explicitly evolutionary in nature provides the most coherent and powerful descriptor of biodiversity, and yet evolutionary thinking is generally neglected in most plans to manage our environment. It is critical, however, that an evolutionary perspective be incorporated into conservation planning (Hendry et al. 2010).

\section{Evolution generates and maintains biodiversity and ecosystems}

Biodiversity is a product of evolution and, in the broadest sense, includes all biological variation on Earth, present and past. Organisms, the relationships among them, and the relationships between organisms and their abiotic environment are constantly changed by evolution. Given this, it might seem obvious that the principles of evolutionary biology should have a major role in regional planning for land or water uses as well as for managing ecosystems. Thus, an understanding of evolutionary processes necessarily complements current emphasis on their ecological counterparts. It is easy to acknowledge that 'nothing in biology makes sense except in the light of evolution'. However, it is necessary to go beyond the generality of this statement and find ways to apply our understanding of evolutionary processes to the conservation and management of ecosystems (e.g. Sarkar and Margules 2002).

\section{Incorporating evolution in the valuation of biodiversity for sustainable use}

The recognized need for sustainable use while conserving and managing ecosystems creates the need to evaluate the benefits and costs of such use. Biodiversity is notoriously difficult to measure, not only because it is a complex concept involving genetic, species and community or ecosystem diversity, but also because it needs to be considered at different spatial scales. In appraising biodiversity, it is crucial to consider both current and possible future uses of species diversity by humans as well as its evolutionary potential. Typically, valuation exercises focus on current uses, given that future uses are harder to assess.

Another issue in measuring biodiversity arises from the often-used approach that treats groups of taxa with similar traits as a significant functional unit. In this view, particular taxa within functional groups are considered redundant and interchangeable. Such measures necessarily ignore subtle or unrecognized differences within groups that may have crucial roles in the community. For instance, species with similar

Keywords. Ecosystem services; evolutionary potential; evosystem services; sustainable use 
functional traits but different ecological preferences may be critical in sustaining ecosystem function in the face of environmental change (Isbell 2010).

Available biodiversity measures are often difficult to translate into meaningful measures for economics. In general, valuation for sustainability involves valuation of economic, socio-cultural and ecological benefits and costs. Of these, the first (economic) can be directly perceived and is relatively easy to valuate, while the other two (socio-cultural and ecological) are less tangible and more difficult to valuate. Ecological benefits are usually viewed in terms of biodiversity and ecosystem services. However, in most valuation exercises the emphasis tends to be on ecosystem services, because biodiversity is difficult to measure and appraise. Furthermore, as mentioned above, biodiversity has benefits that are related not to ecosystem services but to economic or socio-cultural values in the form of biodiversity products or less easily monetized benefits. These difficulties result in lip service to the valuation of biodiversity. A more complete picture is one that integrates functional diversity (and its links to ecosystem process) with species or genetic diversity (with its links to option values). The knowledge of evolutionary processes is critical in providing these links.

The valuation of the potential future uses of species and genetic diversity considers option values. Here, the evaluator tries to take into account the fact that, by preserving biodiversity, choices are increased for using biodiversity in the future. Conserving biodiversity over the long term means we should take into account future, rather than just current, value while deciding whether to exploit a particular biological resource irreversibly. This is the option value of biodiversity conservation. Here, option values are due to two kinds of benefits of biodiversity: those that are presently unknown (or not yet relevant), and those that are expected to emerge from future unpredictable responses to environmental change (Faith 2013). In conserving biodiversity, we choose to maintain different gene pools, species and communities. This is similar to developing a balanced portfolio of investments, where our intent is to include different kinds of stocks that might react very differently to changes in the financial market. Just as we do not want to put all our resources into a single investment, we do not want to leave the future of life on Earth at the mercy of one or a few species. We also maintain biodiversity in order to have a portfolio of possible future benefits for humans.

A fundamental practical problem with such a valuation system lies in the fact that evolution, a key process for the conservation of ecosystems, is often left out of these calculations. Indeed, while ecological processes are regularly used to model the present and future of ecosystems, evolutionary processes are generally ignored. Evolutionary processes generate biodiversity and shape diversity through natural selection in the face of environmental change and thereby ensure the ability of populations, communities and ecosystems to respond to change.

\section{Evosystem services result from evolutionary mechanisms}

The importance of accounting for evolutionary dynamics in the valuation of natural systems has been explicitly included in the concept of 'evosystem services', which are defined as 'all of the uses or services to humans that are produced from the evolutionary process' (Faith et al. 2010). Under this concept, evolutionary mechanisms in evosystems are viewed as 'evolutionary factories' that generate two types of evosystem services. The first is an enormous reservoir of current biodiversity that results from past evolution and that is today exploited for food, shelter, clothing, medicine and fuel. This evosystem service is the focus of current attempts to conserve biodiversity and ecosytems, and to enable sustainable development for the future of humankind.

Sustainability underlies the importance given to agro-biodiversity in conservation efforts, especially in developing countries such as India. The vast assemblage of wild relatives of crop plants with valuable variation in traits across and within species, also the result of evolution, is critical for successful domestication and continued exploitation of food and other crop plants (e.g. Arora and Nayar 1984). The rice variety IR36, released in 1976, incorporated genetic material from 13 parents from six different nations. Critically, it contained a gene for resistance to the Rice grassy stunt virus (RGSV), which came from a single accession of the wild rice, Oryza nivara, collected in Uttar Pradesh. This variety became 'the world's most popular rice' (Ling et al. 1970; IRRI 1982; Brar and Khush 1997). The significant, and often unpredictable, role of landraces and wild relatives in sustainable agriculture underlies the concern that transgene flow might undermine these evolutionary storehouses of variability (Gepts and Papa 2003, 
Kumar et al. 2008). Such direct benefits are obvious and relatively easy to valuate, even if the role of evolution in generating such benefits may be far from obvious.

The second type of evosystem service is constituted by the evolutionary processes themselves, including mutation, selection, genetic drift, speciation, and diversification, that continuously operate and produce new diversity for new uses and new solutions to new problems. These processes may be relatively slow, operating at the longer, classically understood evolutionary tempo, or relatively fast, at ecological time scales, leading to rapid evolution. It is therefore imperative to include the preservation of genetic diversity and evolutionary potential in planning for sustainability. This second type of evosystem service falls into the intangible class of benefits whose importance is becoming more widely recognized in a wide range of situations.

If we consider evolutionary potential, for instance, it is clear that evolutionary responses have been implied to be very important in relation to harvesting (e.g. Hendry et al. 2010), pollution (Levinton et al. 2003), invasive species (Cox 2004), and climate change (Bernardo et al. 2007; Urban et al. 2012). Evolutionary processes are also crucial in relation to the emergence of infectious diseases (Pybus and Rambaut 2009), the development of resistance to antibiotics (Davies and Davies 2010) and pesticides (Heap 1997) and GM crops (Tabashnik 2008; Dhurua and Gujar 2011). These studies reveal a wide range of situations of interest to humans, where the presence of genetic diversity was critical in enabling change, both beneficial and detrimental, over ecological time scales. Over larger time scales, historical evolutionary analyses may reveal unforeseen genetic potential and mechanisms of resilience in the face of environmental change. For instance, phylogeographic studies of the white-bellied shortwing suggest that multiple glacial refugia in the Western Ghats may have driven the current distribution and population structure of these birds (Robin et al. 2010). Species distribution models over the past 20,000 years suggest that Saxifraga florulenta, a tertiary relictual species endemic to the southwestern Alps, survived in micro-refugia during periods of strongly unfavorable climate and later expanded to newly suitable areas when the climatic conditions changed and became more favourable (Patsiou et al. 2013). Similarly, on a larger scale, biodiversity in neotropical rainforests is believed to have increased in response to rapid warming driven by increases of $\mathrm{CO}_{2}$ in the geological past, suggesting that many tropical plant species may already have the genetic variability to cope with climate warming (Jaramillo et al. 2010; Jaramillo and Cardenas 2013).

When we consider evolutionary heritage, it is clear that knowledge of phylogenetic relationships can inform conservation priorities (Faith 1992; Whiting et al. 2000; Pérez-Losada et al. 2009). In this context, the 'phylogenetic diversity' (PD) measure, which incorporates phylogenetic and trait differences among species, is particularly useful (Faith 1992, Forest et al. 2007). Phylogenetic analyses are successfully used in bioprospecting to determine the potential for new discoveries of piscine venoms (Smith and Wheeler 2006) and natural products from microbes (Pacharawongsakda et al. 2009). The importance of traditional knowledge and understanding evolutionary relationships for bioprospecting purposes is also evident. Using a genus-level phylogenetic tree representing 20,000 species from three unrelated floras (Nepal, New Zealand, and the Cape of South Africa), it was shown that the 1500 species used in traditional medicine in the three regions are clustered in the phylogeny. In other words, related plants from the three regions are used to treat similar medical conditions, indicating that the same medical component of these plants was independently discovered (Saslis-Lagoudakisa et al. 2012). These examples only represent a small fraction of the questions in biodiversity science that can be studied using evolutionary approaches.

Given that the importance of applying evolutionary principles in conservation and human well-being is not yet widely acknowledged, we designed the 'Evolutionary Approaches to Biodiversity Science Training Workshop' (http://www.diversitas-biogenesis.org/). The goal of this workshop is to provide a current outlook on some of the most relevant evolutionary approaches to the study of biodiversity, as well as to exemplify the types of questions that can be addressed through an evolutionary perspective. Workshops have been held in Bonito (Brazil, June 2012) and Banda Aceh (Indonesia, March 2013) in association with meetings of the Association for Tropical Biology and Conservation (ATBC). Following up on the success of the first two editions and based on feedback from trainees, advanced workshops focusing on specific approaches are planned; introductory workshops will continue in different geographic locations.

Our intent is to communicate the fundamental relevance of evolution in the production, maintenance, and future of biodiversity (Donoghue et al. 2009). By equipping young biologists with theoretical and methodological tools, we are ensuring that the next generation of biodiversity scientists has the resources to envision and plan for a sustainable, biodiverse future. 


\section{References}

Arora RK and Nayar ER 1984 Wild Relatives of crop plants in India. (New Delhi: National Bureau of Plant Genetic Resources) $90 \mathrm{pp}$

Bernardo J, Ossola RJ, Spotila J and Crandall KA 2007 Interspecies physiological variation as a tool for cross-species assessments of global warming-induced endangerment: validation of an intrinsic determinant of macroecological and phylogeographic structure. Biol. Lett. 3 695-698

Brar DS and Khush GS 1997 Alien introgression in rice. Plant Mol. Biol. 35 35-47

Cox GW 2004 Alien species and evolution: The evolutionary ecology of exotic plants, animals, microbes, and interacting native species (Washington, DC: Island Press)

Daily GC 1997 Nature's services, societal dependence on natural ecosystems (Washington, DC: Island Press)

Davies J and Davies D 2010 Origins and evolution of antibiotic resistance. Microbiol. Mol. Biol. Rev. 74 $417-433$

Dhurua S and Gujar GT 2011 Field-evolved resistance to Bt toxin Cry1Ac in the pink bollworm, Pectinophora gossypiella (Saunders) (Lepidoptera: Gelechiidae), from India. Pest Manag. Sci. 67 898-903

Donoghue MJ, Yahara T, Conti E, Cracraft J, Crandall KA, Faith DP, Häuser C, Hendry, et al. 2009 bioGENESIS: Providing an evolutionary framework for biodiversity science. DIVERSITAS Report No. 6, $52 \mathrm{pp}$

Faith DP 1992 Conservation evaluation and phylogenetic diversity. Biol. Conserv. 61 1-10

Faith DP 2013 'Biodiversity’ The Stanford Encyclopedia of Philosophy, (ed) EN Zalta http://plato.stanford.edu/entries/ biodiversity/

Faith DP 2012 Common ground for biodiversity and ecosystem services: the 'partial protection' challenge. F1000 Research http://f1000research.com/articles/common-ground-for-biodiversity-and-ecosystem-services-the-partialprotection-challengel

Faith DP, Magallón S, Hendry AP, Conti E, Yahara T and Donoghue MJ 2010 Evosystem services: an evolutionary perspective on the links between biodiversity and human well-being. Curr. Opin. Environ. Sustain. 2 66-74

Forest F, Grenyer R, Rouget M, Davies TJ, Cowling RM, Faith DP, Balmford A, Manning JC, et al. 2007 Preserving the evolutionary potential of floras in biodiversity hotspots. Nature 445 757-760

Gepts P and Papa R 2003 Possible effects of (trans)gene flow from crops on the genetic diversity from landraces and wild relatives. Environ. Biosafety Res. 2 89-103

Heap IM 1997 International survey of herbicide-resistant weeds. W. Soc. Weed Sci. 50 27-29

Hendry AP, Lohmann LG, Conti E, Cracraft J, Crandall KA, Faith DP, Häuser C, Joly CA, et al. 2010 Evolutionary biology in biodiversity science, conservation, and policy: A call to action. Evolution 64 1517-1528

International Rice Research Institute IRRI 1982 IR36: the world's most popular rice. (IRRI: Philippines) 35 pp

Isbell FI 2010 Causes and consequences of changing biodiversity. Nature Edu. Knowl. 111

Jaramillo C, Ochoa D, Contreras L, Pagani M, Carvajal-Ortiz H, Pratt LM, Krishnan S, Cardona A, Romero M, et al. 2010 Effects of rapid global warming at the paleocene-eocene boundary on neotropical vegetation. Science 330 957-961

Jaramillo C and Cardenas A 2013 Global warming and neotropical rainforests: A historical perspective. Annu. Rev. Earth Planet. Sci. 41 741-766

Kumar V, Bellinder RR, Brainard DC, Malik RK and Gupta RK 2008 Risks of herbicide resistant rice in India: a review. Crop Prot. 27 320-329

Levinton JS, Suatoni E, Wallace W, Junkins R, Kelaher B and Allen BJ 2003 Rapid loss of genetically based resistance to metals after the cleanup of a superfund site. Proc. Nat. Acad. Sci. 100 9889-9891

Ling KC, Aguiero VM, Lee SH 1970 A mass screening method for testing resistance to grassy stunt disease of rice. Plant Dis. Reptr. 56 565-569

Pacharawongsakda E, Yokwai S and Ingsriswang S 2009 Potential natural product discovery from microbes through a diversity-guided computational framework. Appl. Microbiol. Biotechnol. 82 579-586

Patsiou T, Conti E, Zimmermann N, Theodoridis S, Randin C 2013 Topo-climatic microrefugia explain the persistence of a rare endemic plant in the Alps during the last 21 millennia. Global Change Biology. doi: 10.1111/gcb.12515

Pérez-Losada M, Bond-Buckup G, Jara GG and Crandall KA 2009 Conservation assessment of southern South American freshwater ecoregions on the basis of the distribution and genetic diversity of crabs in the genus Aegla. Conserv. Biol. 23 692-702

Pybus OG and Rambaut A 2009 Evolutionary analysis of the dynamics of viral infectious disease. Nature Rev. Genet. 10 540-550

Robin VV, Sinha A and Ramakrishnan U 2010 Ancient geographical gaps and paleo-climate shape the phylogeography of an endemic bird in the sky islands of Southern India. PLOS ONE 5 e13321 doi: 10.1371/journal.pone.0013321

Sarkar S and Margules CR 2002 Operationalizing biodversity for conservation planning. J. Biosci. 27 299-308 
Saslis-Lagoudakisa CH, Savolainen V, Williamson EM, Forest F, Wagstaff SJ, Baral SR, Watson MF, Pendry CA, et al. 2012 Phylogenies reveal predictive power of traditional medicine in bioprospecting. Proc. Nat. Acad. Sci. 109 15835-15840

Smith WL and Wheeler WC 2006 Venom evolution widespread in fishes: a phylogenetic road map for the bioprospecting of piscine venoms. J. Hered. 97 206-217

Tabashnik BE 2008 Delayng insect resistance to transgenic crops. Proc. Natl. Acad. Sci. USA 105 19029-19030

Urban M, De Meester L, Vellend M, Stoks R and Vanoverbeke J 2012 A crucial step toward realism: responses to climate change from an evolving metacommunity perspective. Evol. Appl. 5 154-167

Whiting AS, Lawler SH, Horwitz P and Crandall KA 2000 Biogeographic regionalization of Australia: Assigning conservation priorities based on endemic freshwater crayfish phylogenetics. Animal Conserv. 3 155-163

R Geeta $^{l, *}$, Lúcia G Lohmann ${ }^{2}$, Susana Magallón ${ }^{3}$, Daniel P Faith ${ }^{4}$, Andrew

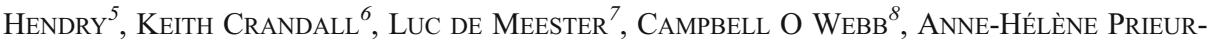
Richard $^{9}$, Makiko Mimura ${ }^{10}$, Elena CONTI ${ }^{11}$, Joel Cracraft ${ }^{12}$, Felix Forest $^{13}$, Carlos Jaramillo ${ }^{14}$, Michael Donoghue ${ }^{15}$ and Tetsukazu Yahara ${ }^{16}$

${ }^{1}$ Department of Botany, University of Delhi, Delhi 110 007, India

${ }^{2}$ Departamento de Botânica, Universidade de São Paulo, Rua do Matão, 277, 05508-090,

São Paulo, SP, Brazil

${ }^{3}$ Departamento de Botanica, Instituto de Biologla, Universidad Nacional Autonoma de Mexico, 3er Circuito de Ciudad Universitaria, Del. Coyoacan, Mexico, D.F. 04510, Mexico

${ }^{4}$ The Australian Museum, 6 College St., Sydney, NSW 2010, Australia

${ }^{5}$ Redpath Museum and Department of Biology, McGill University, 859 Sherbrooke St. W., Montreal, Quebec, Canada H3A 2 K6

${ }^{6}$ Computational Biology Institute, George Washington University, Ashburn, VA 20147, USA

${ }^{7}$ Laboratory of Aquatic Ecology and Evolutionary Biology, Charles Deberiostraat 32 bus 2439, B-3000 Leuven, Belgium

${ }^{8}$ Arnold Arboretum of Harvard University, 1300 Centre Street, Boston, MA 02131, USA

${ }^{9}$ DIVERSITAS, clo Muséum National d'Histoire Naturelle (MNHN), Maison Buffon, 57 rue Cuvier - CP 41, 75231 Paris Cedex 05, France

${ }^{10}$ Division of Genetics and Cell Biology, Tamagawa University, 6-1-1 TamagawaGakuen, Machida, Tokyo, 194-8610, Japan

${ }^{11}$ Institute of Systematic Botany and Botanic Garden, University of Zurich, Zollikerstrasse 107, 8008 Zurich, Switzerland

${ }^{12}$ Department of Ornithology, American Museum of Natural History, Central Park West at 79th St., New York, NY 10024 USA

${ }^{13}$ Jodrell Laboratory, Royal Botanic Gardens, Kew, Richmond, Surrey, TW9 3DS, UK

${ }^{14}$ Smithsonian Tropical Research Institute, Panama city, Panama

${ }^{15}$ Department of Ecology and Evolutionary Biology, Yale University, 21 Sachem Street, P.O. Box 208105, New Haven, CT 06520, USA

${ }^{16}$ Department of Biology, Kyushu University, 6-10-1 Hakozaki, Higashi-ku, Fukuoka 812- 8581, Japan *Corresponding author (Email,rgeeta53@gmail.com) 